\title{
Research on the Relationship between Chinese Express Delivery Industry and Economic Development Based on PVAR Model
}

\author{
Shichang Shen, Jianmei Shen \\ School of Mathematics and Statistics, Qinghai Nationalities University, Xining, China \\ Email: 13909785766@163.com
}

How to cite this paper: Shen, S.C. and Shen, J.M. (2021) Research on the Relationship between Chinese Express Delivery Industry and Economic Development Based on PVAR Model. Open Journal of Statistics, 11, 329-336.

https://doi.org/10.4236/ojs.2021.112019

Received: March 29, 2021

Accepted: April 23, 2021

Published: April 26, 2021

Copyright $\odot 2021$ by author(s) and Scientific Research Publishing Inc. This work is licensed under the Creative Commons Attribution International License (CC BY 4.0).

http://creativecommons.org/licenses/by/4.0/

\begin{abstract}
Based on the panel vector autoregressive model (PVAR) and the panel data of China's 31 provinces from 2010 to 2019, this paper conducts a quantitative analysis on the dynamic balance relationship between China's express business volume and economic development status in recent 10 years. The results show that: Firstly, there is a long-term equilibrium relationship between the development level of express industry and the economic development level; Secondly, the relationship between them presents regional heterogeneity (that is, the East, Centre and the West show different characteristics); Finally, in the short term, the development of express delivery industry and economic development can well drive each other, but in the long term, this trend is not obvious, and the economic impact of express delivery industry has a certain lag.
\end{abstract}

\section{Keywords}

Express Industry, Economic Development, PVAR, Regional Effect

\section{Introduction}

Express delivery industry, a new industry that has just developed in the $21^{\text {st }}$ century, is an important part of logistics. It is characterized by its speed, which can deliver goods to the target place in a very short time. In recent years, with the development of long-distance e-commerce, China's express industry has been developing every rapidly, and has been maintaining a relatively fast development level. In the context of the rapid development of the Internet economy, many buyers and sellers who have never met in the past complete transactions only 
through E-mail and remote payment, which has promoted the development of the express delivery industry. For exploring the relationship between express delivery industry and economic development, Meng Ran [1] (2014) analyzed the development process and current situation of output elasticity, through the study, the author finds that in the regions with high development level of express delivery industry, the output elasticity of express delivery industry to economic growth is large, while in the regions with low development level, the output elasticity of express delivery industry to economic growth is small, and in some regions, the express delivery industry has not played a role in economic growth. Han Song and Liu Jia [2] (2015) analyzed the impact of express delivery industry on the national economy from three aspects: the interdependence between industries, the ripple effect of industries and the employment-absorbing capacity. Yao Zhencheng and Liang Neifeng [3] (2018), based on grey correlation analysis, found that economic growth has a great promoting effect on express delivery industry, and the author thinks that the volume of express delivery presents a positive correlation to the economic development, and the economic development has a great role in promoting the volume of express delivery. Li Jie, Chen Bi and Zhong Yulan [4] (2017) took Shanghai as an example to construct a time series econometric model and carry out an empirical study with OLS method, it is found that there is a positive relationship between the development of express delivery industry and economic development, and the growth of express delivery volume will bring the corresponding regional GDP growth. Fan Meiling, Xu Haoxiong and Zhang Lin [5] (2018) selected the data since the economic crisis and built a linear model to analyze the relationship between the two based on the background of the great development of the Internet. In this paper, based on the relevant indicators of China's express industry and economic development from 2010 to 2019, the panel vector autoregressive model is adopted to conduct a quantitative analysis on the dynamic balance relationship between them.

\section{Theoretical Basis}

Holtz-Eakin (1987) was the first to use the PVAR model to analyze the interaction between endogenous variables of panel data. What he studied was the vector autoregressive model of panel data, which uniformly regarded all variables as endogenous variables and analyzed the relationship between each variable and its lagging items. Using panel data, PVAR model can effectively solve the problem of individual heterogeneity and fully consider the effects of individual and time. The general manifestation of PVAR model is as follows:

$$
y_{i t}=\alpha_{i, 0}+\sum_{j=1}^{p} \alpha_{i, j} y_{i, t-j}+\gamma_{i}+\theta_{t}+\varepsilon_{i t}
$$

where $i$ and $t$ represent region and time, $j$ represents lag period, $p$ stands for lag $p$ period, $\gamma_{i}$ is individual effect, $\theta_{t}$ is time effect, and $\varepsilon_{i t}$ is random disturbance term. 


\section{Empirical Analysis}

\subsection{Data Selection}

In this paper, GDP per capita (unit: 100 million yuan) and express business volume (Q, unit: 10 thousand pieces) were selected, with a time span from 2010 to $2019(\mathrm{~T}=10)$ and a cross section of 31 provinces, municipalities and autonomous regions in China $(\mathrm{N}=31)$. The sample was selected from China Statistical Yearbook (wap.stats.gov.cn). Descriptive statistical results of the data are shown in Table 1. In this paper, according to the comprehensive development status of each province, province and autonomous region, it is divided into three regions (see Tan Xingfen [6] "The Division and Characteristics of the Three Economic Zones of China"): the eastern zone, the central zone and the western zone.

\subsection{Unit Root Test}

As the panel data used has the property of time series, in order to avoid false regression and false regression, unit root test after taking natural logarithm of the data found that the series was not stable at the $5 \%$ test level, so the results were not presented. Therefore, here, ADF test and PP-Fisher test are used to conduct unit root test on variable sum ( $\Delta$ denoted by first-order difference), and the results are shown in Table 2. As can be seen from Table 2, the ADF statistics and PP-Fisher statistics of the sequence $\Delta \ln G D P$ and $\Delta \ln Q$ are both less than the critical value at the significance level of $5 \%$, so the data is stable, that is, the two sequences after the first-order difference are $I(1)$ sequences.

\subsection{Co-Integration Test}

Because, $\Delta \ln G D P$ and $\Delta \ln Q$ are $I(1)$ sequences, the conditions for co-integration

Table 1. Descriptive analysis of panel data.

\begin{tabular}{cccccc}
\hline Variable & Observations & Mean & Std. Dev. & Min & Max \\
\hline GDP & 310 & $22,254.03$ & $19,254.78$ & 512.9 & $107,986.9$ \\
Q & 310 & $79,378.93$ & $189,461.1$ & 162.7 & $1,680,594$ \\
\hline
\end{tabular}

Table 2. Unit root test of panel data.

\begin{tabular}{cccc}
\hline Variables & Methods & $\Delta \ln G D P$ & $\Delta \ln Q$ \\
\hline \multirow{2}{*}{ All } & ADF & $-9.88304(0.0000)^{\star *}$ & $-3.58041(0.0000)^{\star *}$ \\
& PP-Fisher & $-14.6591(0.0000)^{\star *}$ & $-4.97305(0.0000)^{\star *}$ \\
East & ADF & $-4.41416(0.0000)^{\star *}$ & $-6.49047(0.0000)^{\star *}$ \\
& PP-Fisher & $-6.20695(0.0000)^{\star *}$ & $-8.13232(0.0000)^{\star *}$ \\
Centre & ADF & $-5.37542(0.0000)^{\star *}$ & $-8.38310(0.0353)^{\star *}$ \\
& PP-Fisher & $-1.90823(0.0000)^{\star *}$ & $-1.87852(0.0302)^{\star *}$ \\
\hline \multirow{2}{*}{ West } & ADF & $-4.41285(0.0000)^{\star *}$ & $-4.54140(0.0000)^{\star *}$ \\
& PP-Fisher & $-7.47213(0.0000)^{\star *}$ & $-5.53729(0.0000)^{\star *}$ \\
\hline
\end{tabular}

Note: $\Delta$ indicates first-order difference; ${ }^{* *}$ represents a significance level of $5 \%$. 
test are met. The first-order difference of variables is stable, which is also the premise of the football co-integration test. The co-integration test of the data is performed, using the Pedroni test, the KAO test, and the Combined Individual test. The results are shown in Table 3 . The results show that at the significance level of $5 \%$, there is a co-integration relationship between and sequence, indicating that there is a long-term dynamic equilibrium relationship between the development of express industry and economic development.

\subsection{Establishment and Estimation of PVAR Model}

\subsubsection{Optimal Delay Selection}

Usually, the optimal lag order of the model is determined according to the information criteria AIC, BIC and HQIC. The results are shown in Table 4, and the optimal lag order of the three different economic belts in the east, the centre and the west is determined to be 5,4 and 4 respectively.

\subsubsection{Granger Causality Test}

Granger causality test was further carried out on the $\triangle \ln G D P$ and $\triangle \ln Q$ sequence, as shown in Table 5. It's all mutual Granger causality of the East, the Centre and the West region. On this basis, the impulse response analysis and variance decomposition results of the model are shown in Figures 1-3 and Table 6 , respectively.

Table 3. Co-integration test (test results and test results).

\begin{tabular}{ccc}
\hline Method & Statistic & Prob \\
& Panel v-Statistic & $4.130149(0.0000)$ \\
& Panel rho-Statistic & $-1.849579(0.0322)$ \\
Perpdroni & Panel PP-Statistic & $-4.642120(0.0000)$ \\
& Panel ADF-Statistic & $-3.373187(0.0000)$ \\
& Group rho-Statistic & $1.515126(0.9351)$ \\
Kao & Group PP-Statistic & $-3.034731(0.0012)$ \\
\hline Hypothesized No. of CE(s) & Fisher Stat. ${ }^{*}$ from trace test $)$ & Fisher Stat. ${ }^{*}($ from max - eigen test $)$ \\
\hline None & Group ADF-Statistic & $-5.520373(0.0000)$ \\
\hline At most 1 & AD9.7 (0.0000) & $444.8(0.0000)$ \\
\hline & $179.6(0.0000)$ & $179.6(0.0000)$
\end{tabular}

Table 4. Optimal lag order.

\begin{tabular}{ccccc}
\hline Area & Lag order & AIC & BIC & HQIC \\
\hline East & 5 & $-0.972754^{*}$ & $0.556865^{\star}$ & $-0.390266^{\star}$ \\
Centre & 4 & -3.89645 & $-2.21501^{\star}$ & -3.35854 \\
West & 4 & $0.470693^{*}$ & $1.99068^{\star}$ & $1.02027^{\star}$ \\
\hline
\end{tabular}


Impulse-responses for 5 lag VAR of Ingdp Inq
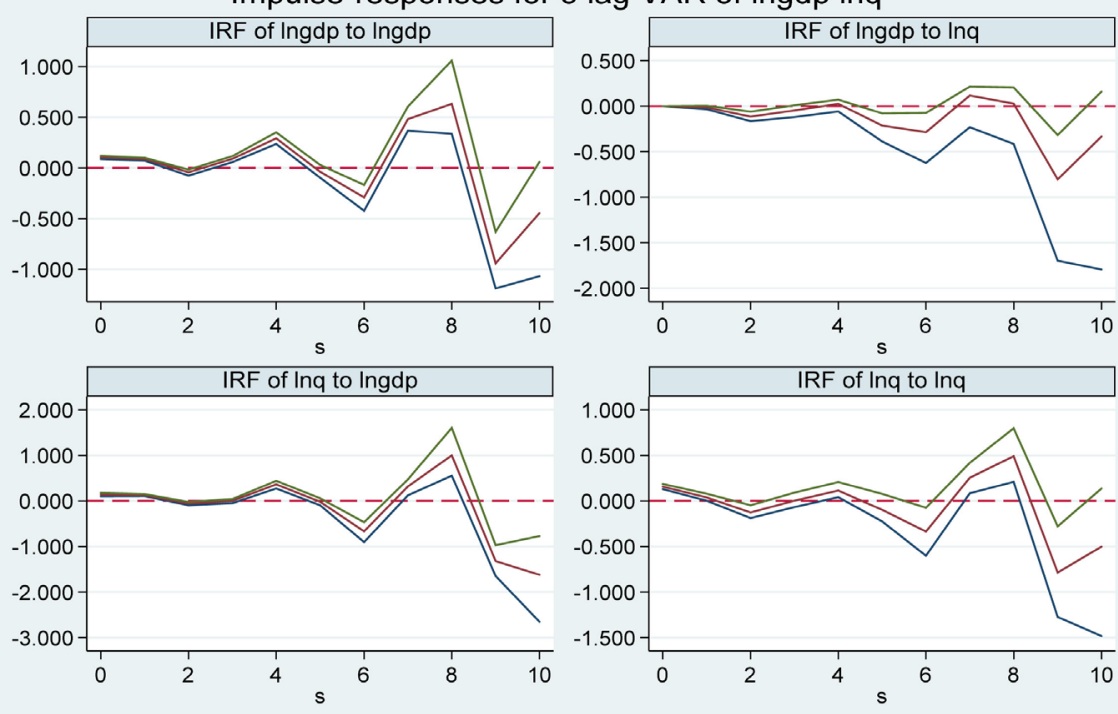

Errors are $5 \%$ on each side generated by Monte-Carlo with 200 reps

Figure 1. Impulse response figure of the East.

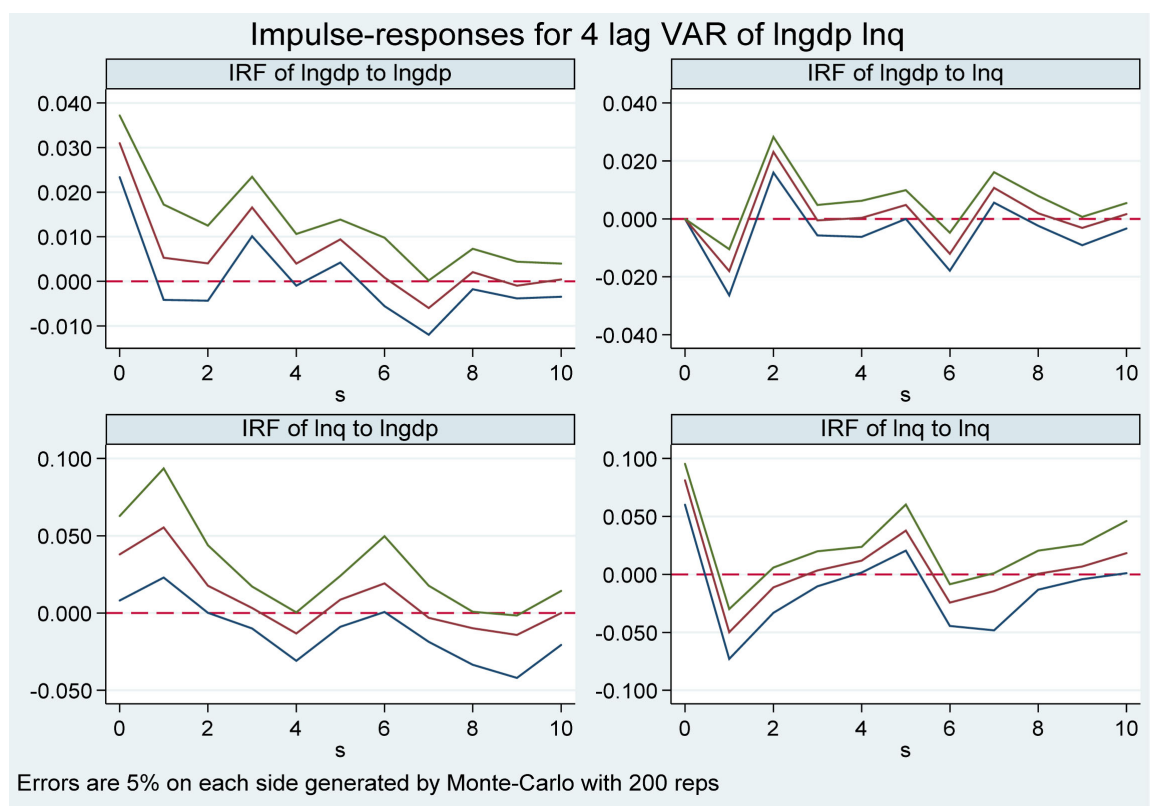

Figure 2. Impulse response figure of the centre.

Table 5. Granger casuality test.

\begin{tabular}{cccc}
\hline H0 & East & Centre & East \\
\hline $\begin{array}{c}\text { The former sequence is not the } \\
\text { Granger cause of the latter }\end{array}$ & lag $=5$ & lag $=4$ & lag $=4$ \\
& Statistic & Statistic & Statistic \\
lnGDP-lnQ & $2660.5(0.0000)$ & $275.13(0.0000)$ & $23.851(0.0000)$ \\
LnQ-lnGDP & $4174.2(0.0000)$ & $400.96(0.0000)$ & $88.653(0.0000)$ \\
Conclusion & Reject & Reject & Reject \\
\hline
\end{tabular}


Impulse-responses for 4 lag VAR of Ingdp Inq
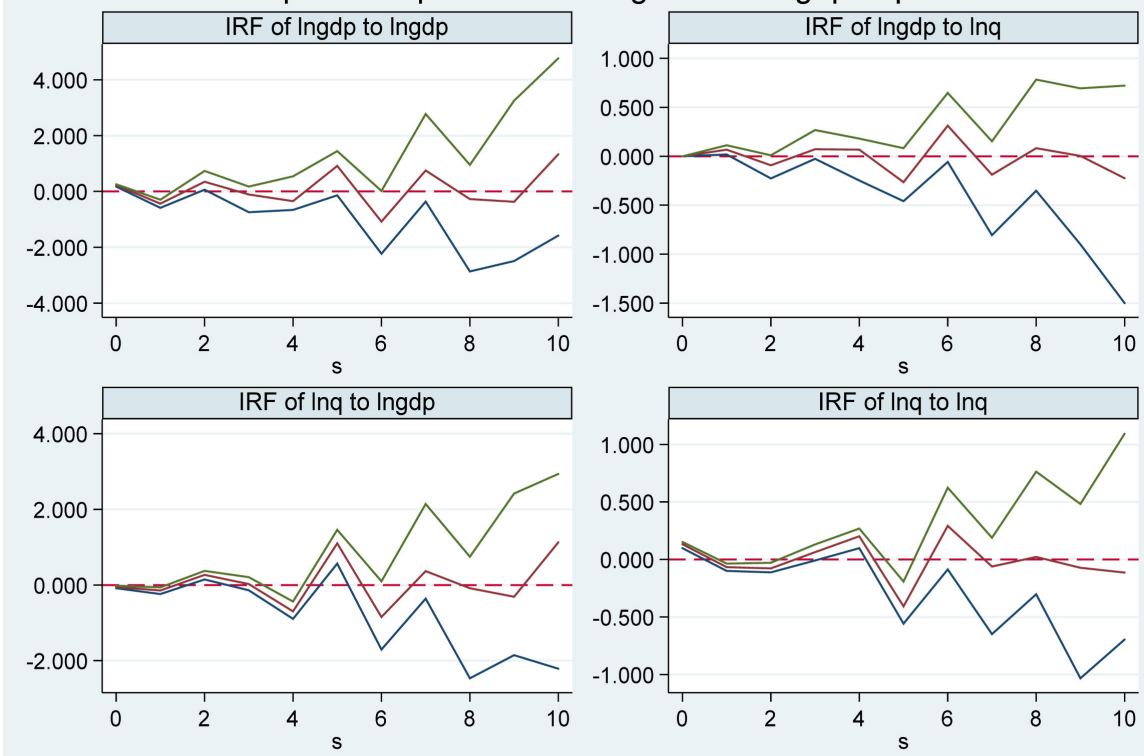

Errors are $5 \%$ on each side generated by Monte-Carlo with 200 reps

Figure 3. Impulse response figure of the West.

Table 6. Sub-regional variance decompositions.

\begin{tabular}{|c|c|c|c|c|c|c|c|}
\hline \multicolumn{2}{|c|}{ Area } & \multicolumn{2}{|c|}{ East } & \multicolumn{2}{|c|}{ Centre } & \multicolumn{2}{|c|}{ West } \\
\hline $\mathrm{s}$ & Variables & $\operatorname{lngdp}$ & $\ln q$ & lngdp & $\ln q$ & $\operatorname{lngdp}$ & $\ln q$ \\
\hline 1 & $\operatorname{lngdp}$ & 1.000 & 0.000 & 1.000 & 0.000 & 1.000 & 0.000 \\
\hline 1 & $\ln q$ & 0.445 & 0.555 & 0.180 & 0.820 & 0.133 & 0.867 \\
\hline 2 & $\operatorname{lngdp}$ & 0.990 & 0.010 & 0.752 & 0.248 & 0.982 & 0.018 \\
\hline 2 & $\ln q$ & 0.580 & 0.420 & 0.332 & 0.668 & 0.521 & 0.479 \\
\hline 3 & $\operatorname{lngdp}$ & 0.597 & 0.403 & 0.538 & 0.462 & 0.965 & 0.035 \\
\hline 3 & $\ln q$ & 0.483 & 0.517 & 0.343 & 0.657 & 0.771 & 0.229 \\
\hline 4 & $\operatorname{lngdp}$ & 0.641 & 0.3593 & 0.598 & 0.402 & 0.954 & 0.046 \\
\hline 4 & $\ln q$ & 0.483 & 0.517 & 0.344 & 0.656 & 0.747 & 0.253 \\
\hline 5 & lngdp & 0.874 & 0.126 & 0.601 & 0.399 & 0.956 & 0.044 \\
\hline 5 & $\ln q$ & 0.756 & 0.244 & 0.348 & 0.652 & 0.888 & 0.112 \\
\hline 6 & lngdp & 0.649 & 0.351 & 0.610 & 0.390 & 0.935 & 0.065 \\
\hline 6 & $\ln q$ & 0.726 & 0.274 & 0.320 & 0.680 & 0.883 & 0.117 \\
\hline 7 & $\operatorname{lngdp}$ & 0.580 & 0.420 & 0.573 & 0.427 & 0.929 & 0.071 \\
\hline 7 & $\ln q$ & 0.776 & 0.224 & 0.323 & 0.677 & 0.886 & 0.114 \\
\hline 8 & lngdp & 0.733 & 0.267 & 0.554 & 0.446 & 0.931 & 0.069 \\
\hline 8 & $\ln q$ & 0.747 & 0.253 & 0.320 & 0.680 & 0.890 & 0.110 \\
\hline 9 & lngdp & 0.841 & 0.159 & 0.554 & 0.446 & 0.931 & 0.069 \\
\hline 9 & $\ln q$ & 0.780 & 0.220 & 0.324 & 0.676 & 0.890 & 0.110 \\
\hline 10 & $\operatorname{lngdp}$ & 0.681 & 0.319 & 0.552 & 0.448 & 0.934 & 0.066 \\
\hline 10 & $\ln q$ & 0.758 & 0.242 & 0.331 & 0.669 & 0.892 & 0.108 \\
\hline
\end{tabular}




\subsubsection{Impulse Response Analysis}

The impulse response measures the short-term effect of one variable on another after a shock of one unit standard deviation. Figure 1 shows the impulse response of the eastern region. Figure 1 shows the response of the express industry to the impact of the economic level, which is positive on the whole, indicating that the development of the express industry in the eastern region has a positive impact on the economic growth. The figure on the right shows the response to the impact of economic growth on the development of express delivery industry, which is negative on the whole, indicating that the development of express delivery mainly depends on itself and the driving effect of economic development on it is very limited. Similarly, it can be seen from Figure 2 and Figure 3 that the express delivery industry in central and western China has no obvious influence on the economic growth, while the economic growth has a significant impact on the development of the express delivery industry.

\subsubsection{Variance Decomposition}

Variance decomposition is used to analyze the contribution of structural shocks to endogenous variables. It is a deep description and analysis of the interaction and change trend of each variable at present and in the future. As can be seen from Table 6, in terms of economic development, the contribution rate of economic level in the eastern, central and western regions was 100\% at the beginning, and then declined somewhat. The contribution rate of express delivery industry development level was zero at the beginning, then also increased. But the express industry development and economic development in the mutual influence between difference is obvious, such as the eastern region, the express industry development a rise will affect the economic development, and with the increase of period, express delivery industry contribution rate showed a trend of overall rising steadily, shows that the eastern region express industry plays a positive effect on economic growth. However, the economic development did not drive the development of express delivery industry at the beginning, and although the influence of economic development on the express delivery industry has increased, the influence is small, indicating that the development of the express delivery industry mainly depends on itself, and the driving effect of the economy on it is limited. However, the express delivery industry in central and western China has little or no impact on the economic growth, while the economic growth has some help to the development of the express delivery industry.

\section{Conclusions and Suggestions}

This paper features three economic belt regions on the express industry development and economic development by using the 2010 to 2019 panel data of 31 provinces. The study found that: 1) There is a long-term dynamic equilibrium relationship between them, and they are each other's granger causality. 2) In the east express industry plays a positive effect on economic growth, but economic 
development leading role on the development of the eastern region express industry co., LTD. 3) The central and western regions express development impact on economic growth is on the decline, effect is very small, but economic growth has a very good role to express industry development.

Based on this, the following two suggestions are proposed:

1) Strengthen the construction of express industry development system, especially in the eastern region. In the long run, the development of express delivery industry will become a carriage driving economic growth, so it is necessary to speed up the development system of the Courier industry and strengthen its services.

2) Accelerate the pace of economic construction, especially in the western region. Economic development will drive the development of the express delivery industry. Therefore, the central and western regions can promote the development of the express delivery industry by making use of the utilization efficiency of manpower or adjusting the economic structure.

\section{Fund}

This work is supported by the National Science Foundation of China (No.11561056).

\section{Conflicts of Interest}

The authors declare no conflicts of interest regarding the publication of this paper.

\section{References}

[1] Meng, R. (2014) Empirical Research on the Role of Express Industry on China's Economic Growth. Beijing Jiaotong University, Beijing.

[2] Han, S. and Liu, J. (2015) Research on the Impact of Express Delivery Industry on National Economy Based on Input-Output Model. Statistics and Management, 11, 41-43.

[3] Yao, Z.C. and Liang, N.F. (2018) Research on the Relationship between Guangdong Express Industry and Economic Development Based on Grey Relation Analysis. Economy and Management, 5, 108-109.

[4] Li, J., Chen, B. and Zhong, Y.L. (2017) An Empirical Analysis of the Influence of Express Delivery Industry on Economic Development-Taking Shanghai as an Example. Financial Economics, 14, 57-59.

[5] Fan, M.L., Xu, H.X. and Zhang, L. (2018) Research on the Influence of Express Delivery Industry on China's Economic Development: Based on the Background of Internet Development. Southern Entrepreneurs, 2, 155-156.

[6] Tan, X.F. (1986) The Division and Characteristics of the Three Major Economic Zones in the East, Middle and West of China. Chinese Nationalities, 9, 9. 